\title{
UMA FUGA A VÁRIAS VOZES
}

One fugue for several voices

LAMAELA, Inês ${ }^{1}$

\begin{abstract}
Resumo
Na Música, uma fuga é uma composição onde várias vozes dialogam, perguntam e respondem, perseguindo-se entre si num contraponto rico em simetrias e inversões. No contexto de uma prisão, a palavra fuga adquire um significado mais complexo que vai para além da fuga do corpo às paredes e ao arame farpado da reclusão: o corpo está preso, mas o espírito não se consegue algemar. Na apresentação de hoje contam-se histórias de como a música tocada ao piano deu asas para voar. Do contraponto entre as vozes dos participantes de 2 projetos em duas prisões portuguesas faz-se o caminho que revela novas formas de fazer Música na Comunidade, explorando os princípios da inclusão, da democratização e da participação ativa como fundamentos de todo o trabalho.
\end{abstract}

\begin{abstract}
In Music, an escape is a composition where several voices dialogue, ask and respond, pursuing each other in a rich counterpoint in symmetries and inversions. In the context of a prison escape the word acquires a more complex meaning that goes beyond the body's escape to the walls and barbed wire of the prison: the body is stuck, but the spirit can not handcuff. Today's presentation tells stories of how piano music gave wings to fly. From the counterpoint between the voices of the participants of two projects in two Portuguese prisons is the path that reveals new ways of making music in the community, exploring the principles of inclusion, democratization and active participation as foundations of all work.
\end{abstract}

Palavras-chave: Prisão; Música na Comunidade; Piano; Narrativa.

Key-words: Prison; Community Music; Piano; Narrative.

Data de submissão: fevereiro de 2019 | Data de aceitação: junho de 2019.

${ }^{1}$ INÊS LAMELA - Universidade de Aveiro, INET-md, PORTUGAL. Email: ineslamela@gmail.com 


\section{INTRODUÇÃO}

Cada um de nós constrói-se, dia-a-dia, sobre o único que é a sua individualidade. As nossas experiências, ou narrativas, seguem-nos e são, simultaneamente, lideradas por nós. Greene (1995, p. 186) argumenta que "há uma ligação entre a narrativa e a construção da identidade. É importante moldar as nossas próprias histórias”. As artes são um meio que podemos usar para moldar narrativas de nós mesmos e isso não é diferente em uma prisão.

Depois de séculos de evolução que levaram a discursos cada vez mais sofisticados e, em muitos casos, a uma grande distância entre artista e público, atualmente é possível observar que a Arte é reconhecida não apenas na sua dimensão estética intrínseca, mas também como uma ferramenta poderosa de intervenção social. O crescimento exponencial da pesquisa e desenvolvimento de práticas de Música na Comunidade (MC), fundamentada nos princípios da descentralização, da democratização, da igualdade de oportunidades e da participação ativa (McKay \& Higham, 2011), pode ser entendido como um resultado direto dessa mudança de paradigma.

Dentro do caleidoscópio da MC, a prática musical ativa com pessoas que vivem em prisões tem emergido como uma área de especial interesse. As especificidades da prisão, a "instituição total" (Goffman, 1991) onde são "removidas as barreiras que habitualmente separam as várias esferas de vida do individuo (de residência, de trabalho, lúdica), estando estas submetidas a uma gestäo e a uma autoridade comuns, e onde os coparticipantes são os mesmos" (Cunha, 1994, p. 2), fazem de cada projeto musical desenvolvido atrás das grades algo único. Nas secções seguintes, apresentam-se e discutem-se dois projetos desenvolvidos em duas prisões portuguesas. O trabalho em torno do piano como instrumento principal de trabalho musical, de comunicação e de descoberta, é contado através da experiência única dos participantes, num contraponto entre as suas narrativas (as suas vozes) e a análise musical. Numa metáfora musical, chama-se a esta apresentação "fuga a várias vozes". Na música, uma fuga é uma composição onde várias vozes dialogam, perguntam, respondem, e se perseguem entre si, num contraponto complexo. Numa prisão, a palavra "fuga" tem um significado bem diferente e negativo. Mas a fuga aqui se conta é a fuga do espírito, a libertação das paredes, dos castigos, das falhas e das frustrações, através da música feita ao piano. 


\section{O PROJETO "NAS ASAS DE UM PIANO... APRENDO A VOAR"}

O projeto "Nas asas de um piano... aprendo a voar" foi desenvolvido no Estabelecimento Prisional Especial de Santa Cruz do Bispo (Matosinhos, Porto), entre novembro de 2013 e julho de 2014, com a participação de quatro reclusas. Durante estes nove meses de trabalho foram realizadas 91 sessões individuais e 13 sessões de grupo, durante as quais foram preparadas 3 apresentações públicas:

1) “Histórias de um piano ... que ensinou a voar” - uma apresentação para bebés e crianças que viviam, na altura, no EPESCB com suas mães recluídas (havia 15 bebés/crianças no total). Neste concerto foram apresentados os primeiros resultados do trabalho que tinha vindo a ser feito com cada uma das 4 senhoras, ao piano, assim como 4 canções, especialmente pensadas para interagir com as crianças.

2) "Projecto $X "$ - um autêntico exercício de engenharia musical e logística que envolveu a participação de reclusos da prisão de Aveiro e alunos do Mestrado em Música da Universidade de Aveiro, e que implicou a realização de sessões com todos os participantes em Santa Cruz, no Estabelecimento Prisional Regional de Aveiro e na Universidade de Aveiro. O concerto final aconteceu no auditório do Departamento de Comunicação e Arte da Universidade de Aveiro.

3) "Fuga a 4 vozes" - concerto final, um momento a solo e introspetivo. Depois de um concerto para os outros (os bebés e crianças) e com muitos outros (o "Projecto X"), quis que houvesse uma oportunidade de encerrar o projeto numa apresentação focada em cada uma das senhoras e no percurso que cada uma tinha sido capaz de descobrir/percorrer. Consegui que os responsáveis do EPESCB, em coordenação com a Santa Casa da Misericórdia do Porto, alugassem um piano de cauda para este momento final. A voz de cada uma das senhoras fez-se ouvir não só através da música que tocou, mas também através de testemunhos que cada uma delas escreveu sobre a sua experiência, e que foram encenados por um ator convidado, o Bernardo de Almeida, que falou por cada uma delas como se do seu alter-ego se tratasse entre a performance das várias peças que apresentaram. 
O trabalho semanal individual com cada senhora foi feito em três dimensões diferentes. Em primeiro lugar, a dimensão técnica, alicerçada na consciência que, para que a experiência de aprender a tocar fosse, verdadeiramente, completa, teria que haver trabalho de competências físicas do domínio de um instrumento tão complexo como o piano. Em segundo, a dimensão da criatividade, através de improvisação e da composição de peças que ficaram registadas em partitura e que foram apresentadas nos vários concertos. Por último, a dimensão da literacia, aqui entendida como algo que vai além das competências de leitura e escrita, e que incluiu a aprendizagem de vocabulário musical, noções básicas de harmonia ou breves apontamentos sobre a História da Música.

O equilíbrio entre as diferentes linguagens e estilos musicais durante o projeto foi uma das suas características mais importantes: houve tempo para improvisar ou compor em um padrão rock ou bossa nova, tempo para estudar uma peça do repertório clássico de piano, tempo para o tema pop da banda sonora do filme "Titanic", e tempo para aprender uma música popular portuguesa. Às vezes, tudo isso em uma única sessão. Desta forma, os interesses e gostos pessoais de cada uma das senhoras foram combinados com a abordagem de material musical de um domínio mais clássico, num verdadeiro ato de democracia cultural.

Em termos de material escrito usado nas sessões, uma das principais inovações resultantes do projeto foi a criação de partituras gráficas, usando a dedilhação a ser usada e um código de cores para identificação das duas mãos (vermelho para a mão direita, azul para a mão esquerda), em simultâneo com o nome (por extenso) das notas musicais. Estas partituras gráficas foram um importante suporte para a solidificação de praticamente todo o material musical trabalhado durante uma primeira fase do projeto, constituindo-se, ainda que sem a precisão de uma partitura convencional, como um auxiliar de memória eficaz. Em maio, já numa fase adiantada do projeto, foram levadas para as sessões individuais partituras convencionais. De salientar que, apesar de nunca ter sido objetivo do projeto trabalhar a leitura de partitura, foram as próprias reclusas que pediram para o fazer. Neste processo de aprendizagem de leitura musical foram abordadas todas as questões básicas relacionadas com esta competência: leitura nas claves de sol e fá, ritmo, articulação, fraseado e indicações de pedal. 
Como em qualquer outro contexto de contacto e aprendizagem de um instrumento musical, também neste contexto de prisão se considerou, desde o primeiro dia, que seria essencial dar tempo de trabalho individual a cada uma das participantes, no piano onde eram feitas as sessões. Esta questão foi discutida com frequência com a direção do EPESCB, desde o início do projeto. No entanto, por causa das questões logísticas associadas (um guarda prisional para acompanhar e controlar cada reclusa), nunca foi implementada durante os primeiros três meses do projeto. Com o primeiro concerto marcado foi, finalmente, possível convencer os responsáveis do EPESCB da importância do estudo individual para garantir uma apresentação de qualidade. Em meados de fevereiro de 2014, três semanas antes do primeiro concerto, as reclusas foram autorizadas a praticar durante a semana, num horário que contemplava uma hora de estudo diário para cada uma. Este horário de estudo individual manteve-se até ao final do projeto. Para além de melhorar, claramente, a qualidade da performance pianística em si mesma, foi também muito importante na medida em que permitiu que cada reclusa tivesse um momento a sós, durante o qual decidia o que fazer com o seu tempo. Para apoiar este trabalho individual, foram feitas gravações das peças, os chamados playalongs, que cada uma das senhoras andava a trabalhar. Foi dado um $c d$ a cada uma e foi levada para a sala das sessões uma mini aparelhagem.

\section{UMA FUGA A QUATRO VOZES}

São apresentadas, de seguida, as quatro protagonistas do projeto "Nas asas de um piano... aprendo a voar", nome inspirado nos seus próprios comentários. Pelo facto de ter sido desenvolvido principalmente em sessões individuais com cada uma das participantes, foi possível acompanhar de perto a sua narrativa. O grande projeto constitui-se, portanto, como uma soma de quatro projetos únicos e singulares, que se conta através de quatro histórias diferentes, quatro narrativas/vozes da mesma jornada.

Os nomes com que são apresentadas as senhoras são, por questões relacionadas com a sua privacidade e anonimato, fictícios. Não foram, no entanto, escolhidos ao acaso: Marta, Maria João, Helena e Clara remetem para quatro mulheres que, na História da Música e, mais especificamente, na história do piano, são (ou foram) marcantes: as pianistas Marta Argerich e Maria João Pires, a pianista e pedagoga portuense Helena Sá e Costa, e a pianista e compositora do séc. XIX, talvez a primeira mulher a ser reconhecida neste meio, Clara Schumann. 
Nas próximas secções, desenvolve-se o que de único, intimo e particular foi a experiencia de cada uma das quatro reclusas, dando ênfase às singularidades e peculiaridades de cada percurso: a descoberta de talentos da Marta, a vontade da Maria João, a libertação da Helena pela improvisação, a alegria e os afetos da Clara. A narração é feita num presente, na voz da autora como primeira pessoa, sobre a forma como foram vividas as sessões de trabalho.

\section{Marta}

Senhora com um sotaque portuense bem carregado, senta-se ao piano pela primeira vez e diz-me "Olha que ando a precisar [de qualquer coisa nova], ao menos para me pôr o cérebro a trabalhar. Que a gente aqui sente-se muito apagada!". Durante a sua vida na prisão, descobriu uma veia poética e escreveu muitos poemas que guarda religiosamente numa capa. Tem uma tremenda autoconfiança e autoestima, que quase parecem não fazer parte do ambiente da prisão.

A Marta quer tocar sua própria música, não a música dos outros. Mas, com o passar das semanas, entusiasma-se com as músicas que eu escolhi para trabalhar, durante as sessões. Foi especialmente tocante ouvi-la tocar "Gymnopédies" do compositor Erik Satie, numa versão de 4 mãos comigo, no nosso último concerto. Não tem vergonha de mostrar todo o seu orgulho em sua composição, “Anjos d'Amor”, dedicada ao seu filho e seu marido, para a qual escreve um poema que será lido no concerto final. Tem muita energia e é frequente vê-la a dançar, sentada no banco, enquanto toca. É uma senhora muito talentosa, mas um pouco precipitada: erra por não pensar bem no que deve fazer e, por vezes, tenho dificuldades em conseguir que se concentre devidamente. "Eu sou uma estabalhoada...", diz-me, numa das primeiras sessões.

Quer continuar a tocar piano, quando for libertada, mas não sabe se irá ter essa oportunidade. Vai começar a reconstruir a sua vida do zero, depois de sair da prisão, e isso assusta-a. Foi libertada em dezembro de 2014. Entrou na universidade, como era o seu sonho, e espera tornar-se uma Técnica Oficial de Contas. 


\section{Maria João}

Senhora muito ativa, mesmo no interior da prisão, e que se envolve em muitos tipos de iniciativas (desde aulas de ginástica a ações de formação). Dedica-se por inteiro ao projeto e estuda, nas suas palavras, "até lhe doerem os dedos". Diz-me que quer continuar a aprender piano assim que for libertada. Gosta especialmente de estudar repertório escrito, e pede-me para tocar determinadas peças que conhece de outros contextos. Foi muito especial perceber, no último concerto, como tocou todas as peças com imensa atenção a todos os pormenores técnicos e musicais que fomos trabalhando nas sessões.

A Maria João vê a participação no projeto como um começo de algo que pretende continuar "lá fora", assim que for libertada. Tem uma família e uma vida bem estruturadas à sua espera, e procura que a sua reclusão seja uma oportunidade para adquirir mais formação, para se enriquecer. E essa vontade de continuar há de perdurar até final: tem uma academia de música perto de casa onde se quer inscrever, e só tem medo de não se integrar por ser uma escola sobretudo para crianças. Fala sempre no plural, em nome do grupo, quando se refere aos concertos, e sente-se como uma parte de um projeto que é mais do que o trabalho que foi feito individualmente com ela própria. Faz muitos comentários sobre a dificuldade em conseguir fazer determinadas coisas, mas gosta de desafios: "Isto é um curso intensivo, o que me estás a fazer!", “Tu estás a pedir muito! O que vale é que nós te adoramos!...”.

É com a Maria João que tenho oportunidade de trabalhar mais quantidade de repertório, especialmente na segunda metade do projeto. O seu estudo individual refletese na forma como evolui, semana a semana, dando espaço a um trabalho de pormenor, técnico e musical, bastante considerável. Ela própria se vai apercebendo da sua evolução: "Já viste que eu já consigo estar tocar a olhar para a partitura, mas sem olhar para os dedos? É uma evolução muito grande!". Das quatro reclusas, é com a Maria João que desenvolvo a abordagem que mais se aproxima ao trabalho que faço, regularmente, numa sala de aula de piano (ponderando, claro, todas as especificidades de um trabalho realizado num contexto tão particular como o de uma prisão), porque vou percebendo que é a forma que mais se lhe adequa.

Foi libertada em janeiro de 2015. Dias antes de terminar o projeto, pede-me para lhe trazer peças novas e mostra-se interessada em comprar um piano, assim que for libertada, para continuar a tocar. 


\section{Helena}

Umas mãos grandes, dedos grossos e calejados. Nos seus desabafos, conheço uma vida passada que tocou no mais negro a que pode chegar a condição humana, e percebo quanto foi importante a vinda para a prisão para dar a volta à espiral negativa em que estava imersa. Na Helena que está, na primeira sessão, à minha frente, vejo muito pouco desse passado: um grande entusiasmo, manifestamente demonstrado na sua linguagem corporal, uma curiosidade para conhecer o instrumento e a música que dele poderá comunicar. Senta-se pela primeira vez ao piano e observa todo o teclado, desejosa por começar a descobri-lo. O sorriso, o riso e as palmas, tão frequentes ao longo desta primeira sessão (e que se manterão durante todo o projeto), são as provas da sua alegria.

A Helena é uma senhora persistente, confiante e ousada, mas ao mesmo tempo tão frágil, nalguns momentos. Gosta de repetir cada novo bocadinho de música muitas vezes, até que se sinta completamente segura, bate os pés, abana a cabeça e diz "não!" a si mesma, quando se engana. Para muitas vezes para pensar, e desde cedo percebo que, depois de uma informação nova, precisa do seu tempo para a interiorizar. Ouve todas as minhas indicações com muita atenção e não se precipita, organizando o seu pensamento antes de recomeçar a tocar. Vive cada minuto intensamente, e diz-me, já depois deste dia, que quer deixar uma mensagem clara: “Eu consegui!”. Dá tudo de si, e é nos momentos de improvisação que mais claramente se revelam a sua sensibilidade musical e o prazer da descoberta. Com a Helena, todas as sessões começam com uns momentos de improvisação, a quatro mãos, mesmo que o tempo seja pouco para cumprir as tarefas que trago planeadas. Estou consciente que estes minutos são muitos especiais para a Helena. E, no fundo, tenho consciência que me dão, a mim, tanto prazer quanto a ela.

A Helena foi libertada em setembro de 2014. Quer viver todos os momentos em família que perdeu, no passado.

\section{Clara}

Senhora muito delicada, sensível, e com uma visão muito particular do mundo e dos que a rodeiam. Acha que tudo pode ser música, menos as vozes das pessoas. Trabalha nas oficinas das artes, na prisão, e oferece-me, ao longo do projeto, vários presentes pintados por si. É generosa, disponível, e procura incessantemente aprender mais. Ri-se das suas dificuldades e dos seus erros, mas quer, sempre, estar no seu melhor, semana a 
semana. Depois da primeira sessão, desenha, por iniciativa própria, um teclado numa folha de papel onde "treina os dedos" todos os dias, no espaço da sua cela. Conta-me que as outras reclusas, ao vê-la, riem-se à gargalhada.

A Clara quer mesmo aprender e dedica parte do seu tempo a tarefas que, não sendo as mais agradáveis nem motivadoras, lhe parecem ser a única forma de desenvolver as suas competências. Não sabe porquê, mas tem dificuldade em identificar o terceiro dedo e, para se ajudar a si mesma, pinta com verniz um “3”, bem discreto, na unha. Diz-me que se apercebe que tem mais dificuldade em determinadas secções da sua peça e que as repete mais vezes para ficarem mesmo seguras. "Eu hoje acho que estou... em forma!", afirma. Quando não consegue tocar tudo correto, fica frustrada. "Eu estive a treinar isto! Não me admito esta falha!...”. Mas logo me diz para tocarmos mais uma vez.

Sei que, para a Clara, cada nova peça é uma descoberta. Mostra-se sempre entusiasmada com a perspetiva de aprender uma coisa nova. "Eu estou a ver aqui duas bolas... e não sei o que são", diz-me, quando olha para partitura da peça "The pipers are coming" (de John Thompson) pela primeira vez. Digo-lhe que são duas notas tocadas ao mesmo tempo na mão esquerda, ao que me responde, com entusiasmo: “Ai! Que giro!”, querendo experimentar de imediato. Tem um papel muito importante na regulação do trabalho em grupo, nas sessões conjuntas de preparação dos concertos, abdicando de protagonismo ou de determinada tarefa assim que percebe que isso facilitará a minha gestão e organização.

A Clara continua no EPESCB. Pensa no futuro e como poderá continuar a tocar. Se será capaz de aprender mais musicas sozinha, aplicando os conhecimentos que leva desta experiência. Faz planos para tocar com a irmã, quando for libertada.

\section{UM ACORDE SUSPENSIVO - Memórias de um projeto no Teatro Viriato}

Em outubro de 2018 vivi o grande desafio de, em apenas um dia e contando com sensivelmente 6 horas de trabalho em conjunto, tentar dar asas para voar a um grupo de seis reclusos do Estabelecimento Prisional do Campo, em Viseu. O objetivo principal era de, partindo do trabalho musical à volta do piano, construir uma apresentação (necessariamente curta), ao final daquele dia. 
No processo de preparação deste dia, e em conjunto com a Dra. Paula Garcia (Diretora Geral e de Programação do Teatro Viriato) percebi que esta experiência poderia ser muito mais intensa e verdadeiramente diferente se, em vez de ser eu a deslocar-me ao interior do estabelecimento prisional, os reclusos fossem convidados a vir partilhar comigo o palco do Teatro Viriato, dando-lhes a possibilidade não só de estar num palco de uma sala de espetáculo, mas também de ter a experiência de tocar num piano Steinway \& Sons, de uma qualidade fantástica (“o ferrari dos pianos”, como lhes expliquei).

Como mulher, senti este dia de uma forma radicalmente diferente, quando comparado com a minha experiência em Santa Cruz do Bispo. Notei na cara dos seis reclusos, à sua chegada ao Teatro Viriato pela manhã, um ar mais ou menos desconfiado quando olharam para mim, uma "mulher com ar de menina" que lhes propunha um dia à volta do piano, o instrumento das meninas bem-educadas que tocam piano e falam francês. Mas, à medida que os minutos iam passando, a energia e a disponibilidade para entrar nesta viagem eram cada vez maiores. A vontade de participar ia crescendo. $\mathrm{O}$ cuidado em trabalhar cada momento para os melhores resultados possíveis, na apresentação final, ia sendo mais evidente.

Conseguimos preparar quatro momentos musicais diferentes, três deles com vários participantes (ou todos) a tocar em conjunto. Escolhi, para este dia, o tema da "mudança" como mote para alinhar ideias. Com a ajuda do soneto de Camões e da poesia de Eugénio de Andrade, as notas do piano foram ganhando um sentido mais especial. Como lhes disse ao início da manhã, a mudança é algo inevitável na vida de qualquer um de nós, seja qual for a nossa condição e o nosso passado. Almejar uma mudança para melhor fazia parte dos objetivos daquele dia.

No final da apresentação, perguntei aos meus seis companheiros de palco o que tinham sentido naquele dia, ao tocar. De entre eles, houve a resposta espontânea de um, curiosamente o que se mostrou mais reticente e aparentemente menos disponível para se deixar levar pelas asas do piano durante aquele dia. Disse-me: "quando me sentei e toquei estava longe, não estava aqui”. E esta frase diz tudo. Um piano pode, mesmo, dar asas para voar. E assim espero que possa acontecer, no futuro, em muitos outros palcos e com muitas outras pessoas. 


\section{CONSIDERAÇÕES FINAIS}

O trabalho numa prisão só tem um verdadeiro e profundo significado quando se percebe quão importante foi para cada uma das pessoas que partilharam o espaço dos dois projetos acima apresentados. A história da Marta, da Maria João, da Helena e da Clara, ou a história (ainda que breve) dos seis reclusos de Viseu com quem partilhei o palco do Teatro Viriato, são a verdadeira razão por que faz sentido continuar a realizar trabalho com quem se vê, num determinado período da sua vida, privado da sua liberdade.

Na sua essência, o piano não é um instrumento comunitário. Para além disso, historicamente está associado a uma elite da sociedade, porque poucos têm a possibilidade de ter um piano em casa e de aprender a tocá-lo (e, mais uma vez, lembro-me, imediatamente, da imagem da menina bem-educada que "toca piano e fala francês" como paradigma do status social). Nos projetos como os acima descritos descobriram-se novas dimensões do que pode ser a prática musical baseada no piano: a sua essência individualista transformou-se e, de repente, havia seis, oito, dez, doze ou catorze mãos a tocar ao mesmo tempo; a sua condição elitista transformou-se, passando a fazer parte da vida de dez pessoas a quem a sociedade apontou o dedo, condenou e castigou, pelo isolamento.

À volta do piano, a Marta, a Maria João, a Helena e a Clara construíram a sua própria história. E, ainda que numa experiência muito efémera, foi possível testemunhar que também que os seis reclusos do projeto no Teatro Viriato, meus "companheiros de palco" (como tantas vezes lhes chamei, ao longo daquele dia), puderam experimentar essa descoberta de ser (re)descobrir num espaço que, no início daquele dia, lhes parecia estar tão distante das suas vidas. Nas asas de um piano... aprenderam a voar. 


\section{REFERÊNCIAS BIBLIOGRÁFICAS}

Cunha, M. I. (1994). Malhas que a reclusão tece. Questões de identidade numa prisão feminina. Lisboa: Cadernos do Centro de Estudos Judiciários. Disponível em: http://hdl.handle.net/1822/5237

Goffman, E. (1991). Asylums: Essays on the social situation of mental patients and other inmates. London: Penguin Books.

Green, M. (1995). Releasing the Imagination. San Francisco, CA: Jossey-Bass Publishers.

Mckay, G., \& Higham, B. (2011). Community Music: History and Current Practice, its Constructions of 'Community', Digital Turns and Future Soundings. Relatório da Arts and Humanities Research Council. Disponível em: http://usir.salford.ac.uk/18930/ 